\title{
Optimal Production Planning for Manufacturing Systems with Instantaneous Stock-Dependent Demand and Imperfect Yields
}

\author{
Longfei He, ${ }^{1}$ Huangli Peng, ${ }^{1}$ Zhanwen Niu, ${ }^{1}$ Haili Lu, ${ }^{2}$ and Xiangli Xie ${ }^{1}$ \\ ${ }^{1}$ College of Management and Economics, Tianjin University, Tianjin 300072, China \\ ${ }^{2}$ Department of Logistics Management, Wuhan University of Technology, Hubei 430063, China \\ Correspondence should be addressed to Zhanwen Niu; zw.niu@163.com
}

Received 28 September 2014; Accepted 31 December 2014

Academic Editor: Pui-Sze Chow

Copyright (c) 2015 Longfei He et al. This is an open access article distributed under the Creative Commons Attribution License, which permits unrestricted use, distribution, and reproduction in any medium, provided the original work is properly cited.

\begin{abstract}
We consider an EPL model like manufacturing system in presence of production imperfectness and stock-demand dependence simultaneously. During the production process, the system can evolve from in-control state into out-of-control state at any random time, after which the defective items will be generated likely causing quantity loss. Meanwhile, the market demand rate is instantaneously dependent on the timely holding inventory. The manufacturer has to determine his production run length and cycle time by taking into account possible imperfect production, stock-dependent demand, and inventory holding capacity bound. We empolder a model to capture this problem and develop computational algorithm to solve it. We further conduct numerical studies to validate our model and solving method. Sensitivity analyses are reported to show the effect of parameters on the system performance.
\end{abstract}

\section{Introduction}

Managing supply/production uncertainty and changeable demand is always one of the challenging operations since matching them is fairly hard due to instability occurring in two sides, respectively. The firm can suffer managerial issues resulting from both out-of-control production (e.g., Rosenblatt and Lee [1] and Sana [2]) and demand's instantaneous dependence on inventory (e.g., Gupta and Vrat [3] and Urban [4]).

This study involves two aspects of imperfect production and demand-stock dependence in the OM field. Imperfect production property means that defective items can be produced as the production system evolves over time. These imperfect goods will be reworked or deposed directly. As a consequence, the inventory/production planning is spoiled. On the other hand, the demand rate is instantaneously dependent on the timely inventory holding level of quality goods. That means the random production imperfection will eventually affect demand rate through defective items. Setting longer production cycle time to obtain higher inventory can obtain more demand rate resulting in more revenue. However, the longer the production cycle time is, the larger likeliness the imperfect production happens. The annual total cost comprises annual ordering cost and annual inventory holding cost. The production cycle time has opposite effects on these two kinds of cost components. Settling the optimum trade-off between the benefits and corresponding costs for the sake of optimizing the annual total profit is accordingly a crucial problem confronting practitioners.

Our study intends to address this problem by considering the production cycle time and pure production run time length as decision variables in the modeling of the manufacturing system existing in imperfect production and demand-inventory dependence. Specifically, we research the following problem: a manufacturer schedule his/her production annually by deciding each cycle time and run length, whereas the manufacturing system may switch from the incontrol state to the out-of-control state after some time on the account of continuous run of the machine, which takes place at any random time during the production process, also as presented in Shah and Shukla [5]. Moreover, this is not immediately under observation and finally causes the quantity loss. The market demand is sensitive to the on-hand effective inventory excluding the defective goods. 
Although we are concentrating on a new model of production planning contextualized in uncertain yields simultaneously confronting inventory-dependent demand, our modeling processes are to some extent inspired by preceding papers. We give an elucidation on the board literature related to our study below.

The existing relevant literature mainly includes two streams: (1) uncertain production management; (2) inventory/production planning with inventory-dependent demand and their extensions. The production uncertainty incurred by various factors like machine failure, staff changes can always cause the entire production system instable resulting in defective products has inspired extensive studies, such as Rosenblatt and Lee [1], Lee and Rosenblatt [6], Lee and Rosenblatt [7], and a variety of their succeeding papers like Liou et al. [8], Kim and Hong [9], Chung and Hou [10], Guo et al. [11], Hu et al. [12], and so on. Drawing on the celebrated EOQ/EMQ models, early pioneering researches study the production planning optimization considering defection inspecting, restoration cost dependence, detection delay, and maintenance, say, Rosenblatt and Lee [1], Lee and Rosenblatt [6], and Lee and Rosenblatt [7]. Their valuable investigations firstly pull the production planning research closer to the realistic practice where there usually exist in outof-control states for the production process incurring a lot of associated management problems. Furthermore, inspection error types are proposed to be other factors having effects on production planning in an imperfect EMQ manufacturing system; see Liou et al. [8]. From a different perspective, Kim and Hong [9] link the distinction among three types of deteriorating processes to the optimal production run length seeking. Later, Chung and Hou [10] generalize former literature to allow the shortage in the imperfect system. After those static models in this line of research, Sana [2] addresses a production-inventory model with imperfect production and time-varying demand. Their study substantially extends proceeding researches into dynamic situations. In contrast, some recent researches turn to exploring imperfect production planning in the fuzzy environment, like Guo et al. [11] and $\mathrm{Hu}$ et al. [12]. Although the aforementioned literature has done intensive studies on uncertain production incorporating features incurred by itself, that existing research fails to consider the change of demand pattern during the production cycle time. However, they usually assume the demand characteristics are invariable over time, which is just a very special case of our model in this study.

Observation to practice has shown that the real market demand is very complex and it is not a fixed constant, as implied by Levin et al. [13], Silver and Peterson [14], and Gupta and Vrat [3]. Incited by their ground-breaking work, a variety of studies have incorporated stock-dependent rate component into diverse classical inventory models, for instance, by considering items deterioration in Mandal and Phaujdar [15], Datta and Pal [16], and Dixit and Shah [17], involving shelf-space allocation in Baker and Urban [18], allowing stock shortage in Datta and Pal [16], and combining delayed payment schemes in Soni and Shah [19], Min et al. [20], Shah et al. [21], Teng et al. [22], and Zhou et al. [23]. A considerable amount of literature has also addressed relevant problems, like Goh [24], Wee [25], Padmanabhan and Vrat [26], Ray and Chaudhuri [27], Sarker et al. [28], Giri and Chaudhuri [29], Yan and Cheng [30], Mandal and Maiti [31], Chung and Tsai [32], and so on. To learn more about the research of this kind, one is referred to a recent literature review by Urban [4]. Almost all literature mentioned above has only focused on the dependence between demand and inventory with the implicitly obvious a priori prerequisite of completely perfect production, which usually does not fit the practice well. On the contrary, in this paper, we alter that precondition and emphasize the imperfect production frequently occurring in real world.

To the best of our knowledge, few of existing studies have considered the production imperfectness and inventorydemand dependence simultaneously. In contrast, this is just what we concentrate on in the present study. We model the production and demand consumption processes with the aforementioned characteristics as a constrained nonlinear programming system combining different scenarios. Furthermore, our model is distinguished from existing relevant models in several ways: (1) we combine imperfect production and inventory-dependent demand together to explore the optimal production problem; (2) we use optimizing the annual total profit as the objective function instead of annual total cost, which substantially reflects the effect of demandinventory dependence on benefits; and (3) we incorporate the inventory capacity upper boundary into traditional models of imperfect production and inventory holding. We select and develop a suitable computational algorithm to solve the nonlinear programming model with detailed operational steps and procedures. Subsequently, we conduct numerical examples and parameters sensitivity analysis to examine the proposed computational algorithm so as to get some managerial insights (Figures 7, 9, 10, 11, and 13).

The rest of the paper is organized as follows. In Section 2, we sketch the problem features, notations, and its assumptions. In Section 3, we discuss the various scenarios arising from our studied system and derive the associated model. In Section 4, we describe a computational algorithm for solving the constructed model. In Section 5, numerical studies and associated analysis are executed to validate the algorithm proposed. Finally, concluding remarks are given to summarize this study in Section 6.

\section{Problem Characteristics, Notations, and Assumptions}

We study a manufacturing system described like a variant of economic production lot (EPL) model, which is distinct from classical EPL model by characterizing its specific production property and demand changing rules, respectively. On the production side, the system may randomly evolve into an out-of-control state in which a proportion of goods will be generated following some probability distribution. On the demand side, the impact of inventory level on demand is considered. The demand rate consists of the constant demand rate and the inventory level dependent demand rate addressed as

$$
D(t)=a+b I(t), \quad 0 \leq t \leq T,
$$

where $a>0$ and $b>0$. 
So the dynamics where the stock $I(t)$ is depleted at time $t$ can be presented as follows:

$$
\frac{d I(t)}{d t}=-D(t)=-a-b I(t), \quad 0 \leq t \leq T .
$$

The production process can be described like this: for scheduled production cycle time $T$, the manufacturer runs the production line from the beginning to time $S$, that is, $[0, S]$, where $0<S<T$. The production line is closed down in interval $(S, T]$. The manufacturing system may evolve into out-of-control situation incurring defective goods produced randomly. Denoting the production rate $v$ and the production duration $S$ yields aggregate volume $v S$ during the cycle time. It may produce defects after producing continuous $\tau$ time and the system failure results in inferior goods in $\gamma$ proportion of all production during $[\tau, S]$, where $\tau$ obeys an exponential distribution with parameter $\lambda$. During the whole cycle time, the inventory is being consumed by the demand at a rate varying according to the associated stock level at the same time.

The following notations will be used throughout the paper.

\section{Parameters}

$I(t)$ : inventory level at any time $t$ (units),

$D(t)$ : sales rate at time $t$ with $D(t)=a+b I(t)$ where $a>0$ and $b>0$ (units),

$I_{\text {max }}:$ maximum system inventory capacity (units), $v$ : productivity, that is, production rate (units per year),

$\tau$ : random variable of the time moment when production system is changing to uncontrolled state, the probability of which obeys an exponential distribution with parameter $\lambda$ (year),

$\gamma$ : the proportion of defective goods generated after production status changing time $\tau$,

$k$ : fixed setup cost per order (\$/order),

$c$ : variable cost per unit product (\$/unit),

$p$ : the selling price per unit qualified product (\$/unit),

$\sigma$ : the salvage value per unit defective product (\$/unit),

$h$ : holding cost per unit product per unit time (\$/unit item/unit time).

\section{Decision Variables}

$T$ : the whole production and supplying cycle time (year),

$S$ : total production duration, $0<S<T$ (year),

$A C$ : total annual costs, including inventory and ordering costs (\$/year),

$A C_{I}$ : annual inventory costs (\$/year),

$A C_{o}$ : annual ordering costs (\$/year),

$A R$ : total annual revenue, including sales income of qualified products and scrapped income of defective (\$/year),

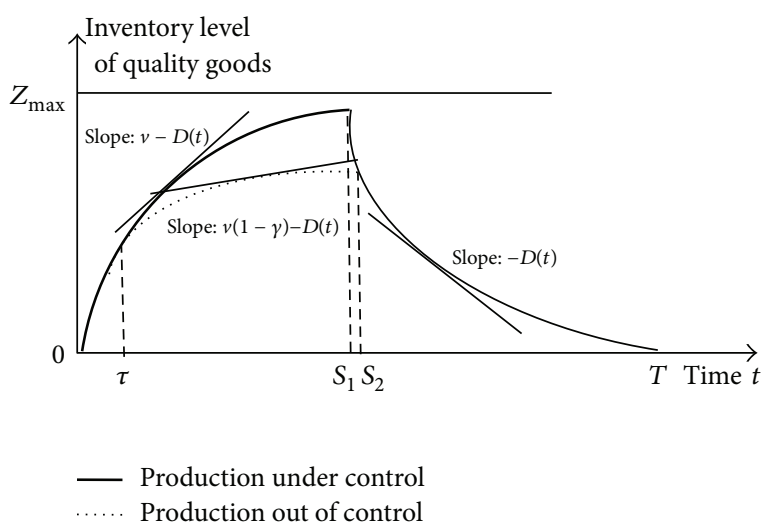

FIGURE 1: Comparison of effective inventory level changing trends in two scenarios.
$A R_{s}$ : sales income of qualified products (\$/year),
$A R_{n}$ : crapped income of defective (\$/year),
$A P$ : total annual profits, $A R-A C$ ( $\$$ /year).

To refine and reflect the essence of our problem, we need assumptions in our model as follows.

(A1) The lead time is zero and the time span is unlimited.

(A2) The production capacity is limited but out-of-stock is not allowed, and productivity is greater than steady section, that is $v>a$.

(A3) After producing continuous $\tau$ time, the system enters an uncontrolled state and defective rate of the product obtained is $\gamma$. After discovering the defective, it needs be scrap processing timely instead of entering the inventory system, where downtime $\tau$ obeys an exponential distribution with parameter $\lambda$.

(A4) Production process is independent in different cycles, which is in each cycle, and the duration $\tau$ of controlled state is independent.

(A5) During each production cycle, the beginning and ending inventory are both zero, that is, $I(0)=0$ and $I(T)=0$.

\section{The Model}

For a given production cycle time $T$, there may be two cases in the whole production process because of the occurrence of imperfect production at time $\tau$. One case is that breakdown time $\tau$ does not occur before the production stopping, that is, $\tau \in[S,+\infty]$, and products obtained in during the period are all qualified products. The other is that the breakdown time $\tau$ occurs during the production process, that is, $\tau \in[0, S]$, and the defective rate is $\gamma(0<\gamma<1)$ from time $\tau$ to time $S$. Assume (1) the upper bound of the stocking system capacity is $I_{\max }$; (2) inventory levels at the beginning and the ending times of the production period are both zero, namely, $I(0)=0$ and $I(T)=0$. We plot the inventory level changing trajectory of qualified products in Figure 1 with two cases, where $S_{1}$ is the stopping time of the continuous production with system under control completely, and so is $S_{2}$ when system out of control occurs. 


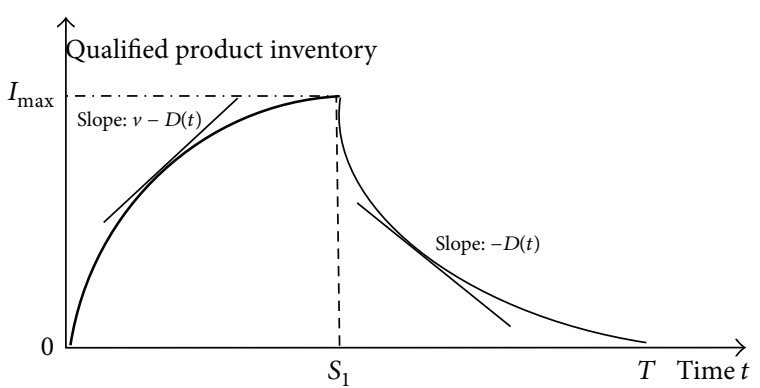

FIGURE 2: The effective inventory level changing trajectory when production is under control consistently.

\subsection{System under Control Completely before Production Stop-} ping. Figure 2 shows the inventory changes in case 1.

The entire inventory cycle time can be divided into two sections, that is, $\left[0, S_{1}\right]$ and $\left[S_{1}, T\right]$. In the period $\left[0, S_{1}\right]$, the system does not produce defective products because the production is carried out under control. During this period, the boundary value is $I_{1-1}(0)=0$ and because $v>a$, the inventory keeps increasing and slope of inventory $I_{1-1}(t)$ is $v-D(t)$, which is given by

$$
\frac{d I_{1-1}(t)}{d t}=v-a-b I_{1-1}(t), \quad 0 \leq t \leq S_{1}
$$

In the period $\left[S_{1}, T\right]$, production ceases. The inventory consumption comes from the fixed demand and the needs with the inventory changing. During this period, the boundary value is $I_{1-2}(T)=0$ and the slope of inventory $I_{1-2}(t)$ is $-D(t)$, which is given by

$$
\frac{d I_{1-2}(t)}{d t}=-a-b I_{1-2}(t), \quad S_{1} \leq t \leq T .
$$

Solving differential equations (4) and differential equations (4), the inventory level in case 1 is $I_{1}(t)$ :

$$
I_{1}(t)= \begin{cases}\frac{(a-v)\left(e^{-b t}-1\right)}{b}, & 0 \leq t \leq S_{1}, \\ \frac{a\left[e^{b(T-t)}-1\right]}{b}, & S_{1}<t \leq T .\end{cases}
$$

The inventory function $I_{1}(t)$ is a continuous function. So where $t=S_{1}$, there is $I_{1-1}\left(S_{1}\right)=I_{1-2}\left(S_{1}\right)$; that is,

$$
\frac{(a-v)\left(e^{-b S_{1}}-1\right)}{b}=\frac{a\left[e^{b\left(T-S_{1}\right)}-1\right]}{b} .
$$

Simplify (6) and then obtain the relationship between $T$ and $S_{1}$, which is given by

$$
S=\frac{1}{b} \ln \frac{a e^{b T}-a+v}{v}
$$

Total annual costs $A C_{1}$ include annual inventory costs $A C_{I 1}$ and annual ordering cost $A C_{o 1}$; that is, $A C_{1}=A C_{I 1}+$ $A C_{o 1}$, in which, annual ordering cost $A C_{o 1}$ consists of two parts: one is the preparation costs for each production and the other is production costs which change with the production volume:

$$
\begin{aligned}
& A C_{I 1}= \frac{h}{T}\left[\int_{0}^{S_{1}} I_{1-1}(t) d t+\int_{S_{1}}^{T} I_{1-2}(t) d t\right] \\
&= \frac{h}{T b^{2}}\left[(v-a) e^{-b S_{1}}+v b S-v-a b T+a e^{b\left(T-S_{1}\right)}\right], \\
& A C_{o}=\frac{1}{T}(c v S+k), \\
& A C_{1}=\frac{h}{T b^{2}}\left[(v-a) e^{-b S}+v b S-v-a b T+a e^{b(T-S)}\right] \\
&+\frac{1}{T}(c v S+k) .
\end{aligned}
$$

Total annual revenue $A R_{1}$ : there are no defects in case 1; total annual revenue $A R_{1}$ equals $A R_{s}$, the sales income of qualified products. Consider

$$
A R_{1}=A R_{s}=\frac{p v S}{T} .
$$

Total annual profit $A P_{1}$ is total annual revenue minus total annual costs, that is, $A P_{1}=A R_{1}-A C_{1}$, which is given by

$$
\begin{aligned}
A P_{1}= & \frac{1}{T}[(p-c) v S-k] \\
& -\frac{h}{T b^{2}}\left[(v-a) e^{-b S}+v b S-v-a b T+a e^{b(T-S)}\right] .
\end{aligned}
$$

Substituting formula (7) into formula (10), then we can get total annual profits function which depends on $T$ :

$$
A P_{1}=\frac{1}{T}\left[\left(p-c-\frac{h}{b}\right) \frac{v}{b} \ln \frac{a e^{b T}-a+v}{v}-k\right]+\frac{a h}{b} .
$$

For any fixed inventory cycle $T$, the ending inventory of system equals zero, that is, $I(T)=0$. This paper will denote $(1 / b) \ln \left(\left(a e^{b T}-a+v\right) / v\right)$ as a critical point of $\tau$, denoted by $\tau_{0}$. Where $\tau>(1 / b) \ln \left(\left(a e^{b T}-a+v\right) / v\right)$, the production processes will follow case 1 . And where $\tau>(1 / b) \ln \left(\left(a e^{b T}-a+v\right) / v\right)$, there will be defective goods in $\left[\tau, S_{2}\right]$. For a detailed analysis, see case 2 .

3.2. System Running Out of Control before the End of Production. To maintain the ending inventory $I(T)=0, S_{2}$ needs to change with $\tau$. Figure 3 shows the qualified inventory changes.

In this case, the entire inventory cycle is divided into three sections, that is, $[0, \tau],\left[\tau, S_{2}\right]$, and $\left[S_{2}, T\right]$. In the period $[0, \tau]$, the system will never produce defective products because 


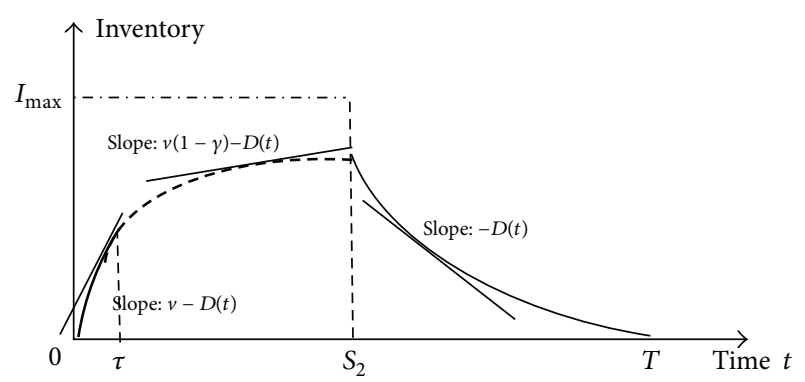

Figure 3: The trajectories of change of the qualified inventory level when the system is out of control.

the production is carried out completely under control. And during this period, the boundary value is $I_{2-1}(0)=0$ and the slope of inventory $I_{2-1}(t)$ is $v-D(t)$; that is,

$$
\frac{d I_{2-1}(t)}{d t}=v-a-b I_{2-1}(t), \quad 0 \leq t \leq \tau \text {. }
$$

In the period $\left[\tau, S_{2}\right]$, production turns into an uncontrolled state. So there will be defective products and the defect rate is $\gamma$. Where $t=\tau$, we have $I_{2-1}(\tau)=I_{2-2}(\tau)$ and the slope of the qualified inventory $I_{2-2}(t)$ is $v(1-\gamma)-D(t)$; that is,

$$
\frac{d I_{2-2}(t)}{d t}=v(1-\gamma)-a-b I_{2-2}(t), \quad \tau \leq t \leq S_{2} .
$$

In the period $\left[S_{2}, T\right]$, the inventory is consumed continuously until it reduces to zero. The boundary values $I_{2-3}(T)=0$ and the slope of inventory $I_{2-3}(t)$ are $-D(t)$; that is,

$$
\frac{d I_{2-3}(t)}{d t}=-a-b I_{2-3}(t), \quad S_{2} \leq t \leq T .
$$

Solve differential equations (12), (13), and (14) and then get the expression of inventory levels $I_{2}(t)$ in case 2 :

$$
I_{2}(t)= \begin{cases}\frac{(a-v)\left(e^{-b t}-1\right)}{b}, & 0 \leq t \leq \tau, \\ \frac{v \gamma e^{b \tau}-(v-a)}{b} e^{-b t}+\frac{\nu(1-\gamma)-a}{b}, & \tau \leq t \leq S_{2}, \\ \frac{a\left[e^{b(T-t)}-1\right]}{b}, & S_{2}<t \leq T .\end{cases}
$$

Obviously, $I_{2}(t)$ is also a piecewise function. It is easy to prove, where $\tau \in[0,(1 / b) \ln ((v-a) / v \gamma)]$, in the period $\tau \leq$ $t \leq S_{2}$, the inventory $I_{2-2}(t)$ is an increasing function. And where $\tau \in\left((1 / b) \ln ((v-a) / v \gamma), S_{2}\right]$, in the period $\tau \leq t \leq S_{2}$, the inventory $I_{2-2}(t)$ is a decreasing function. For details see appendix, Proof 1.

Due to the continuity of the inventory function, where $t=S_{2}$, we have $I_{2-2}\left(S_{2}\right)=I_{2-3}\left(S_{2}\right)$; that is,

$$
-\frac{a-v(1-\gamma)}{b}+\frac{v \gamma-(v-a) e^{-b \tau}}{b e^{-b \tau}} e^{-b S_{2}}=\frac{a\left[e^{b\left(T-S_{2}\right)}-1\right]}{b} .
$$

Simplify (16) and then obtain the relationship among $T$, $\tau$, and $S_{2}$ :

$$
S_{2}=\frac{1}{b} \ln \frac{a e^{b T}+v-a-v \gamma e^{b \tau}}{v(1-\gamma)} .
$$

In case 2, total annual costs $A C_{2}$ also consist of annual inventory costs $A C_{I 2}$ and annual ordering costs $A C_{o 2}$, that is $A C_{2}=A C_{I 2}+A C_{o 2}$. Consider

$$
\begin{gathered}
A C_{I 2}=\frac{h}{T}\left[\int_{0}^{\tau} I_{2-1}(t) d t+\int_{\tau}^{S_{2}} I_{2-2}(t) d t+\int_{S_{2}}^{T} I_{2-3}(t) d t\right] \\
=\frac{h}{T b^{2}}\left\{-v+b v S_{2}-b v \gamma\left(S_{2}-\tau\right)+v \gamma-v \gamma e^{-b\left(S_{2}-\tau\right)}\right. \\
\left.+(v-a) e^{-b S_{2}}+a\left[e^{b\left(T-S_{2}\right)}-b T\right]\right\}, \\
A C_{o 2}=\frac{1}{T}\left(c v S_{2}+k\right), \\
A C_{2}=\frac{h}{T b^{2}}\left\{\begin{array}{c}
-v+b v S_{2}-b v \gamma\left(S_{2}-\tau\right)+v \gamma-v \gamma e^{-b\left(S_{2}-\tau\right)} \\
+(v-a) e^{-b S_{2}}+a\left[e^{b\left(T-S_{2}\right)}-b T\right]
\end{array}\right\} \\
+\frac{1}{T}\left(c v S_{2}+k\right) .
\end{gathered}
$$

In case 2, defects occur during production, so total annual revenue $A R_{2}$ consists of two sections: sales income of qualified products $A R_{S 2}$ and scrapped income of defective annual revenue $A R_{N 2}$ :

$$
\begin{gathered}
A R_{S 2}=\frac{p\left[v S_{2}-\gamma v\left(S_{2}-\tau\right)\right]}{T}, \\
A R_{N 2}=\frac{\sigma \gamma v\left(S_{2}-\tau\right)}{T}, \\
A R_{2}=A R_{S 2}+A R_{N 2}=\frac{p v S_{2}+(\sigma-p) \gamma v\left(S_{2}-\tau\right)}{T} .
\end{gathered}
$$

Total annual profits are equal to the annual revenue minus annual costs (Figure 5), that is, $A P_{2}=A R_{2}-A C_{2}$, which is given by

$$
\begin{gathered}
A P_{2}=\frac{1}{T}\left[(p-c) v S_{2}+(\sigma-p-\omega) \gamma v\left(S_{2}-\tau\right)-k\right] \\
-\frac{h}{T b^{2}}\left\{-v+b v S_{2}-b v \gamma\left(S_{2}-\tau\right)+v \gamma-v \gamma e^{-b\left(S_{2}-\tau\right)}\right. \\
\left.\quad+(v-a) e^{-b S_{2}}+a\left[e^{b\left(T-S_{2}\right)}-b T\right]\right\} .
\end{gathered}
$$


Substituting (17) into (20), then simplify to

$$
\begin{gathered}
A P_{2}=\frac{1}{T}\left[\begin{array}{c}
\left(p-c-\frac{h}{b}\right) \frac{v}{b} \ln \frac{a e^{b T}+v-a-v \gamma e^{b \tau}}{v(1-\gamma)} \\
+\left(\sigma-p+\frac{h}{b}\right) \\
\gamma v\left(\frac{1}{b} \ln \frac{a e^{b T}+v-a-v \gamma e^{b \tau}}{v(1-\gamma)}-\tau\right)-k
\end{array}\right] \\
+\frac{h a}{b} .
\end{gathered}
$$

3.3. Optimizing Annual Total Profit. Objective function: expected annual profits $A P$.

In this paper, the inventory model is divided into case 1 and case 2, according to whether there will be defects in the production. This paper assumes that $\tau$, the moment of appearing defect in $(0,+\infty)$, obeys an exponential distribution with parameter $\lambda$. Therefore the expected annual profits

$$
\begin{aligned}
A P= & E\left[A P_{1}\right]+E\left[A P_{2}\right] \\
= & \int_{\tau_{0}}^{+\infty} A P_{1} \lambda e^{-\lambda \tau} d \tau+\int_{0}^{\tau_{0}} A P_{2} \lambda e^{-\lambda \tau} d \tau \\
= & \frac{1}{T} v\left[\left(p-c-\frac{h}{b}\right)+\gamma\left(\sigma-p+\frac{h}{b}\right)\right] \\
& \cdot \int_{0}^{(1 / b) \ln \left(\left(a e^{b T}-a+v\right) / v\right)} \lambda e^{-\lambda \tau} \frac{1}{b} \\
& +\frac{1}{T}\left\{\gamma v\left(\sigma-p+\frac{h}{b}\right)\right\} \\
& \cdot\left[\left(\frac{1}{\lambda}+\frac{1}{b} \ln \frac{a e^{b T}-a+v-a-v \gamma e^{b \tau}}{v(1-\gamma)} d \tau\right.\right. \\
& +\frac{1}{T}\left[\left(p-c-\frac{h e^{b T}-a+v}{b}\right) \frac{v}{b} \ln \frac{a e^{b T}-a+v}{v}\right] \\
& \cdot\left(\frac{a e^{b T}-a+v}{v}\right)^{-\lambda / b}-\frac{k}{T}+\frac{h a}{b},
\end{aligned}
$$

under the inventory capacity constraints.

Before discussing the inventory constraints, we should compare $S_{1}$ in case 1 with $S_{2}$ in case 2 .
It is written as follows:

$$
S=\left\{\begin{array}{rr}
S_{1}=\frac{1}{b} \ln \frac{a e^{b T}-a+v}{v}, & \tau>\frac{1}{b} \\
& \cdot \ln \frac{a e^{b T}-a+v}{v} ; \\
S_{2}=\frac{1}{b} \ln \frac{a e^{b T}+v-a-v \gamma e^{b \tau}}{v(1-\gamma)}, & 0 \leq \tau \leq \frac{1}{b} \\
& \cdot \ln \frac{a e^{b T}-a+v}{v} .
\end{array}\right.
$$

It is easy to prove $S_{2} \geq S_{1}$, when they have the same $T$. For details see appendix, Proof 2 .

In case 1 , where $t=S_{1}$, the inventory reaches the maximum, which should be less than $I_{\max }$, that is, $a\left[e^{b\left(T-S_{1}\right)}-\right.$ $1] / b \leq I_{\max }$. In case 2, if $\tau \in[0,(1 / b) \ln ((v-a) / v \gamma)]$, then where $t=S_{2}$, the inventory reaches the maximum. And this time, the inventory should be less than $I_{\max }$, that is, $a\left[e^{b\left(T-S_{2}\right)}\right.$ $1] / b \leq I_{\max }$. If $\tau \in\left[(1 / b) \ln ((v-a) / v \gamma), S_{2}\right]$, then where $t=\tau$, the inventory reaches its maximum. And the inventory should be less than $I_{\max }$, that is, $(a-v)\left(e^{-b \tau}-1\right) / b \leq I_{\max }$.

Then, the inventory constraints are

$$
\begin{array}{ll}
\text { s.t. } \quad & \frac{a\left[e^{b\left(T-S_{1}\right)}-1\right]}{b} \leq I_{\max } \\
& \frac{a\left[e^{b\left(T-S_{2}\right)}-1\right]}{b} \leq I_{\max } \\
& \frac{(a-v)\left(e^{-b \tau}-1\right)}{b} \leq I_{\max } \\
\Longrightarrow \max & \left(\frac{a\left[e^{b\left(T-S_{1}\right)}-1\right]}{b}, \frac{a\left[e^{b\left(T-S_{1}\right)}-1\right]}{b},\right. \\
& \left.\frac{(a-v)\left(e^{-b \tau}-1\right)}{b}\right) \leq I_{\max } .
\end{array}
$$

We can prove that

$$
\begin{aligned}
& \max \left(\frac{a\left[e^{b\left(T-S_{1}\right)}-1\right]}{b}, \frac{a\left[e^{b\left(T-S_{1}\right)}-1\right]}{b}, \frac{(a-v)\left(e^{-b \tau}-1\right)}{b}\right) \\
& =\frac{a\left[e^{b\left(T-S_{1}\right)}-1\right]}{b} .
\end{aligned}
$$

For details see appendix, Proof 3.

So the inventory constraints convert into

$$
\frac{a\left[e^{b\left(T-S_{1}\right)}-1\right]}{b} \leq I_{\max }
$$


Substituting (7) into (26), we have

$$
\frac{a\left[e^{b\left(T-S_{1}\right)}-1\right]}{b}=\frac{a(v-a)\left(e^{b T}-1\right)}{b\left(a e^{b T}-a+v\right)} \leq I_{\max } .
$$

Constraint formula (27) can be changed as follows:

$$
\begin{aligned}
\frac{a(v-a)\left(e^{b T}-1\right)}{b\left(a e^{b T}-a+v\right)} & \leq I_{\max } \Longrightarrow a\left(v-a-b I_{\max }\right) e^{b T} \\
& \leq(v-a)\left(a+b I_{\max }\right) .
\end{aligned}
$$

Since $v>a$, the right side of (28) is a positive constant. And the left side can be divided into two cases.

(1) If $v-a-b I_{\max } \leq 0$, we have $e^{b T}>0$. So the left side of (28) is negative and inequality (28) is always true. Then the inventory capacity constraints have no practical significance.

(2) If $v-a-b I_{\max }>0$, obviously the left side of (28) $g(T)=a\left(v-a-b I_{\max }\right) e^{b T}$ is a monotonic increasing function of $T$. To satisfy the constraints, there should be

$$
0<T \leq T_{\max }=\frac{1}{b} \ln \frac{(v-a)\left(a+b I_{\max }\right)}{a\left(v-a-b I_{\max }\right)}
$$

The inventory capacity constraints are successfully converted into the scope limitation of the decision variable values, which becomes simpler and more intuitive. In summary, the expected annual profits maximization model changes into

$$
\begin{aligned}
\max _{T} A P[T] & \\
= & \frac{1}{T} v\left[\left(p-c-\frac{h}{b}\right)+\gamma\left(\sigma-p+\frac{h}{b}\right)\right] \\
& \cdot \int_{0}^{(1 / b) \ln \left(\left(a e^{b T}-a+v\right) / v\right)} \lambda e^{-\lambda \tau} \\
& +\frac{1}{b} \ln \left(\left(a e^{b T}+v\right.\right. \\
& \frac{1}{T}\left\{\gamma v\left(\sigma-p+\frac{h}{b}\right)\right\} \\
& \cdot\left(\frac{1}{\lambda}+\frac{1}{b} \ln \frac{a e^{b T}-a+v}{v}\right) \\
& \left.\cdot\left(\frac{a e^{b T}-a+v}{v}\right)^{-\lambda / b}-\frac{1}{\lambda}\right]
\end{aligned}
$$

$$
\begin{aligned}
& +\frac{1}{T}\left[\left(p-c-\frac{h}{b}\right) \frac{v}{b} \ln \frac{a e^{b T}-a+v}{v}\right] \\
& \cdot\left(\frac{a e^{b T}-a+v}{v}\right)^{-\lambda / b}-\frac{k}{T}+\frac{h a}{b}
\end{aligned}
$$

$$
\begin{gathered}
\text { s.t. } T_{l b}<T \leq \min \left[\frac{1}{b} \ln \frac{(v-a)\left(a+b I_{\max }\right)}{a\left(v-a-b I_{\max }\right)}, T_{u b}\right] \\
\quad \text { if } v-a-b I_{\max }>0 \\
T_{l b}<T<T_{u b}, \quad \text { if } v-a-b I_{\max } \leq 0 .
\end{gathered}
$$

Model (30) can be regarded as a unary nonlinear programming model. Thus the problem can be transformed into unary nonlinear programming problem.

Formula (22) shows that the profit function AP contains the integral of transcendental functions, and there is no analytic expression. Thus it is difficult to use derivatives and gradient information to prove the concavity of the profit function, and the difficulty and complexity of proving it are far beyond the traditional inventory model. However, $A P[T]$ is a continuous function. According to the maximum and minimum theorem of continuous function nature theorem on a closed interval, we can determine that the profit function $A P[T]$ has a maximum within the specified interval. Based on this, this paper designs the following optimization algorithm.

\section{Computational Algorithm}

There are a variety of commonplace methods to solve nonlinear programming models, for instance, Golden Section, Fibonacci, Interpolation, Bisection, Steepest Descent, Newton, quasi-Newton, and Conjugate Gradient and so on. Those traditional algorithms are simple with fast convergence. However, they have relatively high requirements on initial value and functional structure. For more general computational application, scholars have proposed a variety of intelligent algorithms, such as Genetic Algorithms, Simulated Annealing Algorithm, Ant Colony Algorithm, and Chaotic Mixing Algorithm with their own advantages and broad applications, respectively. To overcome the defects of a single algorithm, integrating several algorithms in solving one problem has been prevailing in optimization field through mutually advantageous complementation among them.

Artificial fish swarm algorithm (AFSA) is one kind of integrated algorithms as above mentioned. Li [33] is among the early batch of studies to propose AFSA, which is an intelligent optimization algorithm based on fish behavior in nature. Peng [34] also demonstrates this approach in detail and compares its advantage to other algorithms. To learn more about the growing path of AFSA, Neshat et al. [35] is a good reference with excellent comprehensive literature review. Imitating and realizing three kinds of individual fish's behavior, that is, feeding and rear-ends, clusters underlie the working basis of the algorithm optimality seeking with the associated system parameters design including fish scale 
size $N$, the step, the congestion factor delta, and the perceived distance visual, $\mathrm{Li}$ et al. [36] and $\mathrm{Li}$ et al. [37]. Although the initial AFSA has lots of obvious virtues, there still exists improving space to abate its some weakness for application, which has been pointed out in detail and also improved to apply in diverse settings, say, Wang et al. [38], Li et al. [37], Huang and Zhou [39], Chen et al. [40], Cheng et al. [41], Peng [42], and Tsai and Lin [43].

Drawing on the fact that the concavity of the profit function $A P[T]$ cannot be clearly identified in this paper, we select the artificial fish school algorithm to solve our problem while we make a substantially specific problem-featured improvement for this algorithm inspired by existing literature aforementioned. Here we develop an improved artificial fish school algorithm by combining the adapting parameters strategy and tabu search heuristics simultaneously to enhance the local search ability and convergence rate of initial ASFA. However, our focus in this study is mainly on formulating, modeling, and analysing the focal managerial problem rather than the algorithm improvement. This proposed algorithm is just served to solve the nonlinear problem and will not be compared with other algorithms. We need to emphasize the fact that comprehensively integrating more extensive computational methods and heuristics together finally distinguishes our algorithm design from that in existing researches.

\subsection{The Parameter Adapting Strategy}

Strategy of Changing Step Length. A fixed step length is usually adopted in most of literature for searching optimizer in an artificial algorithm. The step length will affect the converging rate, speed, and accuracy of the searching process. The longer step length will incur higher converging rate and searching speed, but lower accuracy. On the other hand, a small step size will help local search with a slower global converging rate with higher accuracy. The varying step length will be much better in balancing the converging rate and searching accuracy. In this paper, the step is set as (31), a progressively decreasing function as addressed in Huang and Zhou [39] and Chen et al. [40]:

$$
\text { step }_{\text {gen }+1}=\left(\frac{1}{2}+\frac{1}{\text { gen }}\right) \times \text { step }_{\text {gen }} .
$$

Strategy of Changing the Congestion Factor Delta. In order to speed up the searching rate, avoid falling into the plight of local optimum and premature and suppress the congestion factor. In the iterative process, we adopt the congestion attenuation function set in (32) as presented in detail in Zheng [44] to progressively reduce congestion factor to enhance local search convergence rate:

$$
\text { delta }_{\text {gen }+1}=\varepsilon \times \text { delta }_{\text {gen }}, \quad \varepsilon \in(0,1) .
$$

Strategy of Changing the Perceived Distance Visual. According to Chen et al. [40], we set a perceived distance motion function (33) to make the perceived distance decreases with

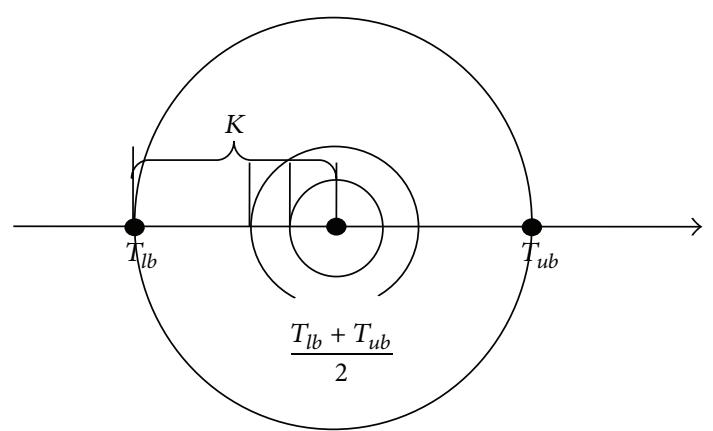

FIGURE 4: One-dimensional neighborhood concept.

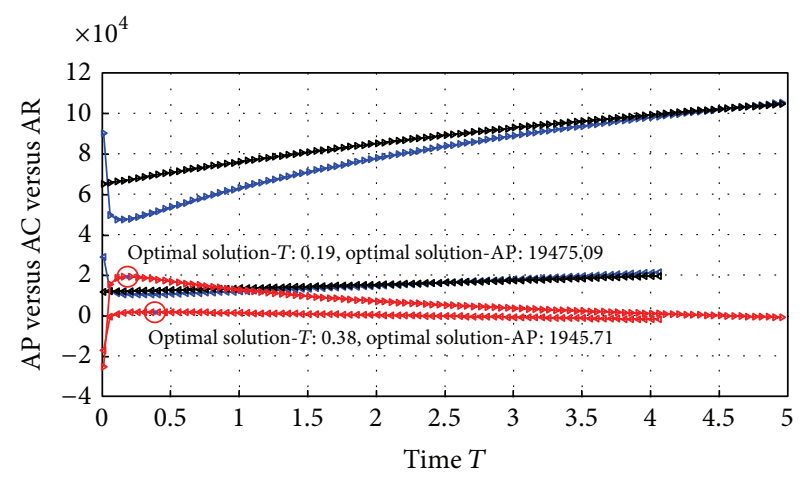

$$
\begin{array}{ll}
\leftarrow \text { AP of case 1 } & \rightarrow \text { AP of case 2 } \\
\leftarrow \text { AC of case 1 } & \rightarrow \text { AC of case 2 } \\
\longleftarrow \text { AR of case 1 } & \rightarrow \text { AR of case 2 }
\end{array}
$$

FIgURE 5: The total annual costs, the total annual revenue, and the total annual profits changes in the two examples.

the iterative number increasing so as to improve the local intensity and solution accuracy:

$$
\text { visual }_{\mathrm{gen}+1}=\left(1-\frac{\text { gen }}{\text { maxgen }}\right) \times \text { visual }_{\mathrm{gen}} .
$$

4.2. Tabu Search Heuristics. To solve the continuous problem in the present study with infinite number of neighbors, using the tabu method of discrete problems cannot make the algorithm effectively searching the global optimal solution. Thus we need to employ the neighborhood tabu for solving. Li et al. [37] elaborate the neighborhood tabu algorithm and propose a two-dimensional neighborhood concept for tabu algorithm. Inspired by their research and considering the specific situation in our current problem, we give out a onedimensional neighborhood concept applied for our problem solving. Divide current feasible solution interval $\left[T_{l b}, T_{u b}\right]$ into $K$ fields falling within a circle with center $\left(T_{u b}+T_{l b}\right) / 2$ and the radius $r$ as shown in Figure 4.

In the gen-th interaction, the current position of $i$ th fish is $T_{i}$, and another position is $T_{j} . T_{j}$ can be the optimal point in the view of the $i$ th fish and also can be the center point or another point. The optimization researching time is denoted as tryno; the optimization coefficient $\theta$ is a randomly generated number between $(0,1)$ by systems. 
The next position of $i$ th fish is determined by the following formula:

$$
T_{i \mid \mathrm{next}}=T_{i}+\theta \times\left(T_{j}-T_{i}\right) .
$$

The process of tabu search is as follows.

Step 1. $T_{i}$ is the current state of artificial fish, $n$ is the counter, and $n=1$.

Step 2. We get a new point $T_{i \mid \text { next }}$ from (34) and then calculate $A P_{i \mid \text { next }}$, and $n=n+1$.

Step 3. Compare the size of $A P_{i}$ with $A P_{i \mid \text { next }}$. If $A P_{i}<A P_{i \mid \text { next }}$, turn to Step 4; if not, go to Step 5.

Step 4. Estimate $T_{i \mid \text { next }}$ belonging to which $k$ neighborhood and determine whether the $k$ th neighborhood exists in the tabu list. If it does not exist, the optimization is successful, and then insert the $k$ th neighborhood into the tabu list. If the tabu list is full, update the list according to the FIFO principle and then end the optimization process. However, if it does exist, go to Step 5.

Step 5. Estimate if $n$ is greater than the maximum attempts time tryno; if so, the optimization process ends in failure. Otherwise, go to Step 2.

4.3. Behavior of a Single Fish. Applying the aforementioned established neighborhood tabu search process to our problem, we get the individual behavior of a single fish including foraging, clustering, rear-end, and searching for historical best fish. Here we introduce these four behaviors.

(1) Foraging. The position of a single fish in current fish swarm is $T_{i}$. The fish randomly chooses a position $T_{j}$ in their sensing range, $T_{j}=T_{i}+$ rand $\times$ visual $_{\text {gen }}$, and then calculate the tabu optimization. If we get the optimization successfully, we take $T_{i \mid \text { next }}$ as the next mobile location of the current fish. If not, randomly move to another step, that is, $T_{i \mid \text { next }}=T_{i}+$ rand $\times$ step gen

(2) Clustering. A single fish position in current fish swarm is $T_{i}$. In this fish's vision, the number of other fish is $n_{f}$ and the optimal position of the fish is $T_{j}$. Compare the size of $A P_{j} / n_{f}$ with delta $\times A P_{i}$. When $A P_{j} / n_{f}>$ delta $\times A P_{i}$, calculate the tabu optimization. If we get the optimization successfully, denote $T_{i \mid \text { next }}$ as the next mobile location of the current fish. If not, turn to foraging behavior.

(3) Rear-End. A single fish position in current fish swarm is $T_{i}$. In this fish's vision, the number of other fish is $n_{f}$ and the geometric center position of the fish is $T_{j}$. Compare the size of $A P_{j} / n_{f}$ with delta $\times A P_{i}$. When $A P_{j} / n_{f}>$ delta $\times A P_{i}$, calculate the tabu optimization. If we get the optimization successfully, denote $T_{i \mid \text { next }}$ as the next mobile location of the current fish. If not, turn to foraging behavior.

(4) Searching for Historical Best Fish. A single fish position in current fish swarm is $T_{i}$. Learning from bulletin board, we have the historical best fish's position $T_{j}$ and then calculate the tabu optimization. If we get the optimization successfully, denote $T_{i \mid \text { next }}$ as the next mobile location of the current fish. If not, turn to foraging behavior.

\subsection{The Overall Improved AFSA Integrating Adapting Parameters and Tabu Search}

Step 1. Set the population size $N$, the moving step step, the congestion factor delta, the perceived distance visual, the maximum number of attempts trynumber, and the length of tabu list Ntabu. Make discrete solution space into $K$ neighborhood and limit the maximum number of iterations maxgen, making gen $=1$.

Step 2. Initialize the fish swarm $\left(T_{1}, T_{2}, T_{3}, \ldots, T_{N}\right)$ in solution space. Calculate the objective function value of current fish swarm $\left(A P_{1}, A P_{2}, A P_{3}, \ldots, A P_{N}\right)$, the optimal fish $T_{j}$ in the current fish swarm, and the historical best fish $T_{\text {best }}$. Record the information of historical best fish on the bulletin board.

Step 3. Each fish in the fish swarm gets three best $T_{i \mid \text { next }}$ through the three best behaviors: clustering, rear-end, and searching for historical best fish. Select a larger target value of $T_{i \mid \text { next }}$ and update their position. After comparing with the historical best fish, update the information on bulletin board.

Step 4. If gen $\geq$ maxgen, then stop the algorithm. If not, make step $_{\text {gen }+1}=((1 / 2)+(1 /$ gen $)) \times$ step $_{\text {gen }}$, delta $_{\text {gen }+1}=\varepsilon \times$ delta $_{\text {gen }}$, and visual $_{\text {gen }+1}=(1-($ gen $/$ maxgen $)) \times$ visual $_{\text {gen }}$. If gen $=$ gen +1 , then turn to Step 3 .

\section{Numerical Studies and Analysis}

5.1. Numerical Examples. To make numerical examples, we set the range of decision variable $T \in(0,5]$.

Example 1. The inventory is limited; the values of each parameter are as follows:

$$
\begin{aligned}
& {\left[a, b, h, k, p, c, \sigma, \lambda, \gamma, v, I_{\max }\right]} \\
& \quad=[300,0.3,8,200,40,30,2,0.1,12,2000,1500] .
\end{aligned}
$$

In this example, $v-a-b I_{\max }>0$, so the limit of inventory maximum capacity is working. According to (29), we calculate the range of maximum value of the decision variable $T$ and compare the result with 5 . Then select a smaller one to be the maximum value of the decision variable $T$. Using the improved artificial fish swarm algorithm, we calculate the optimal solution of this example $[T, A P]=$ $[0.38,1945.71]$. The results and changing trend are shown in Figure 5.

Example 2. The inventory cannot reach the maximum; the values of each parameter are as follows:

$$
\begin{aligned}
& {\left[a, b, h, k, p, c, \sigma, \lambda, \gamma, v, I_{\max }\right]} \\
& \quad=[1000,0.5,15,500,65,45,4,0.3,6,3000,4500] .
\end{aligned}
$$




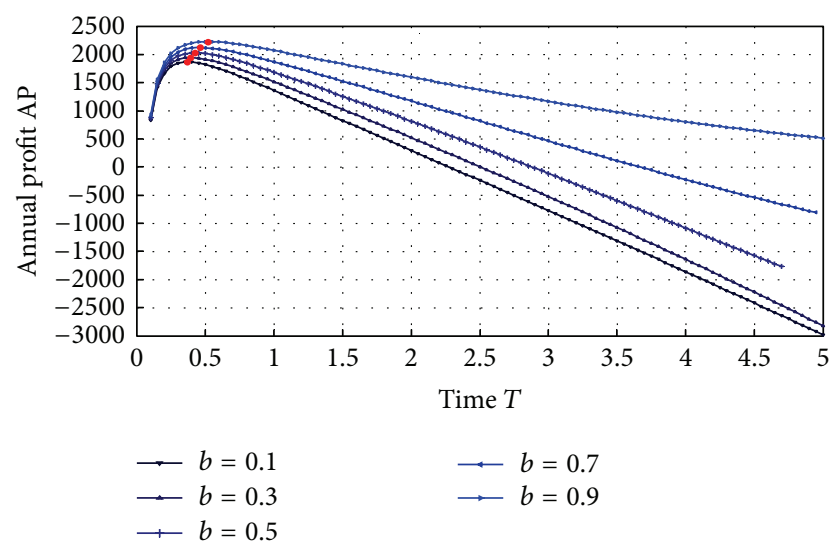

FIGURE 6: The sensitivity analysis of $b$.

In this example, $v-a-b I_{\max } \leq 0$, so the limit of inventory capacity constraints do not need to be considered. The range of decision variable $T$ is $(0,5]$. Within this range, we calculate the optimal solution of this example by iterative optimization, which is $[T, A P]=[0.19,19475.09]$.

\subsection{Sensitivity Analysis. The sensitivity analysis on Example 1} follows.

(1) The Impact of Inventory-Dependence Coefficient $b$ on the Optimal Solution. Assign $b$ with different value and observe the changing tendency of the profit function and the optimization.

As can be seen from Figure 6, with the increase of $b$, the optimal production cycle $T^{*}$ and the maximum annual profits $A P$ also gradually increase. An increasing $b$ implies that the impact of current inventory on the demand is getting greater. The higher the current inventory level is, the greater the demand becomes. Within the inventory capacity, decision maker will try to increase the inventory in order to reach higher sales income. So the maximum annual profit $A P$ gradually increases. But to run out a higher level of inventory, it will require a longer cycle. Therefore the optimal production cycle $T^{*}$ will show an increasing trend.

With the change of $b$, range of decision variable $T$ constantly changes. When $b$ is relatively small and $b<$ $(v-a) / I_{\max }$, the maximum value of $T$ is the min one of $(1 / b) \ln \left((v-a)\left(a+b I_{\max }\right) / a\left(v-a-b I_{\max }\right)\right)$ and 5. $(1 / b) \ln ((v-$ $\left.a)\left(a+b I_{\max }\right) / a\left(v-a-b I_{\max }\right)\right)$ is increasing as $b$ increases. When $(1 / b) \ln \left((v-a)\left(a+b I_{\max }\right) / a\left(v-a-b I_{\max }\right)\right) \leq 5$ is satisfied, the maximum value of $T$ also increases, which is reflected on the length changes of the corresponding profit curve. For example, the profit curve is longer with $b=0.7$ than $b=0.5$. When $b$ increases to $b \geq(v-a) / I_{\max }$ and the maximum value of $T$ is the preset 5 , it is not difficult to find out that the upper limit of $T$ becomes 5 with $b=0.9$.

(2) The Impact of Inventory Holding Space Bound $I_{\max }$ on the Optimal Solution. In Figure 7, we plot the profit-time curves varying as the inventory holding capacity changes. The results show that those curves are almost overlapped,

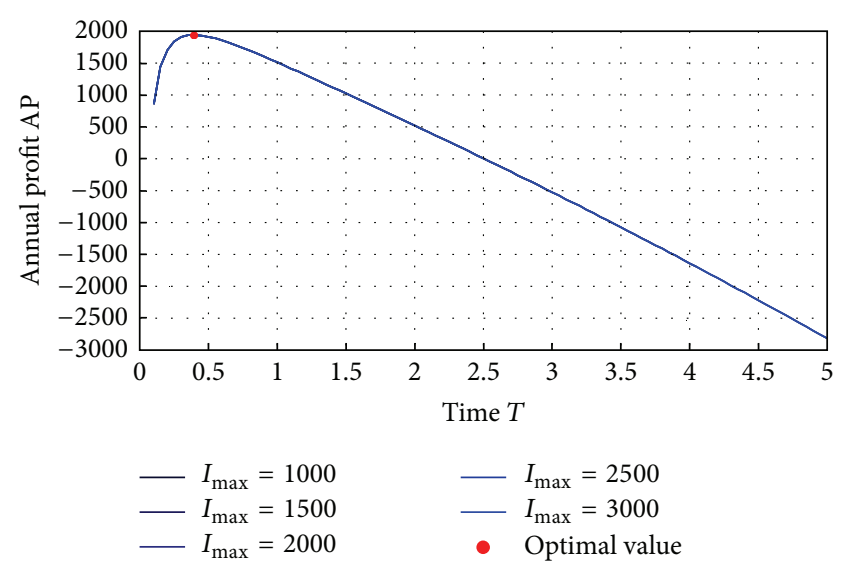

FIGURE 7: The sensitivity analysis of $I_{\max }$.

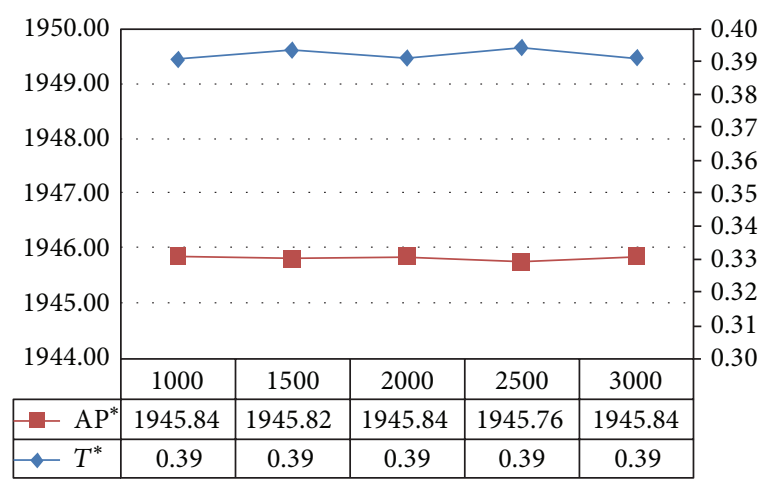

FIGURE 8: The changing trend of $T^{*}$ and $A P^{*}$ when $I_{\max }$ changes.

which implies the high capacity has few influence on the optimal solution. It can also be seen from Figure 8 that when $I_{\max }$ changes, the optimal solution will remain unchanged, based on the premise that the change of $I_{\max }$ still ensures the optimal solution $T^{*}$ within the optimization search scope of $T$; otherwise, the optimal solution $T^{*}$ and the maximum annual profit $A P^{*}$ are both likely to change.

(3) The Impact of Defective Rate $\gamma$ on the Optimal Solution. When there is defective production, it is essentially a loss. With the same production cycle $T$, the annual profit will decrease. When defective rate increases, decision makers will reduce the probability of uncontrolled state. The probability of downtime is exponentially distributed; the shorter the production time is, the smaller the probability of downtime will be. So when $\gamma$ increases, the optimal production cycle $T$ decreases.

(4) The Impact of the Parameter of Exponential Distribution $\lambda$ on the Optimal Solution. $\lambda$ is the parameter of the exponential distribution, which the system downtime $\tau$ obeys. $1 / \lambda$ is the expected value of downtime. With an increasing $\lambda, 1 / \lambda$ gets smaller which means that the system fault occurs quicker. If we keep the fixed production cycle $T$ in this condition, the uncontrolled production state will last longer. There will be more defects in the output and the total profit will decrease. 


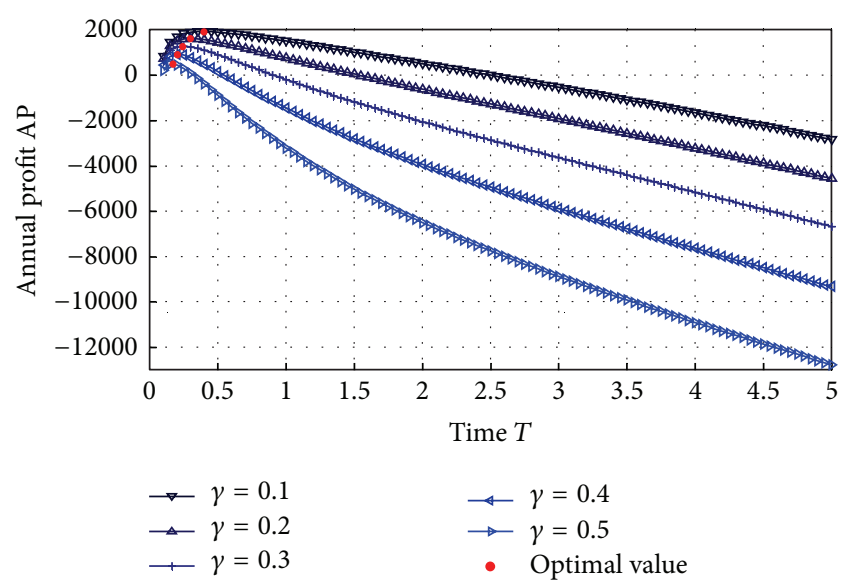

FIGURE 9: The sensitivity analysis of $\gamma$.

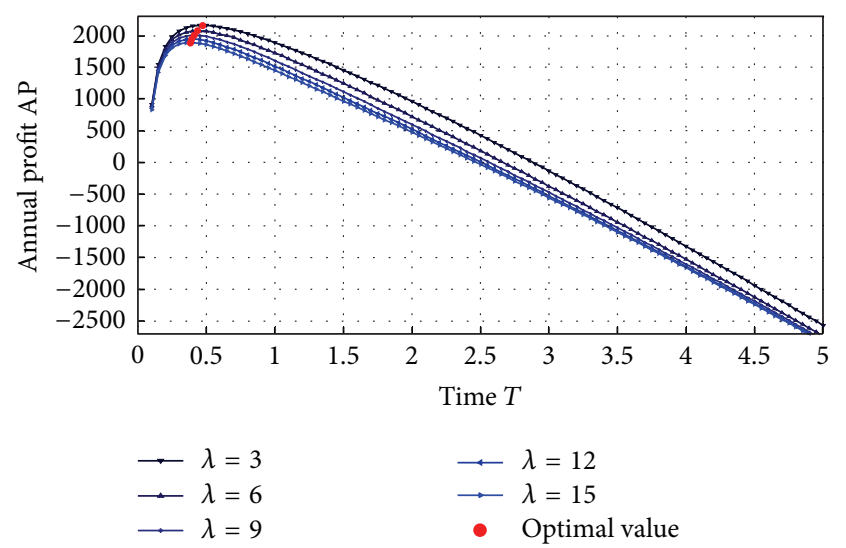

FIgURE 10: The sensitivity analysis of $\lambda$.

Thus the decision maker will decrease the production cycle $T$ to reduce the frequency of system failure and the defective output rate. However, even if $\lambda$ increases continuously, $T$ will not continue reducing. Because a decreasing $T$ means the startup time of this machine in one year increases, the fixed costs increase. Affected by the fixed costs, $T$ will stop decreasing and increase instead.

(5) The Impact of Productivity $v$ on the Optimal Solution. An increasing $v$ means the improvement of production efficiency and acceleration of inventory accumulation. So it can accumulate enough inventory in a shorter production time, and the average system inventory level will improve. As the demand is associated with the current inventory, the demand will also increase. When the value of $T$ is small, the system stays at a relatively low inventory level. With an increasing demand, the increase in sales revenue is greater than the increase in inventory costs, so the annual profit will increase with $v$ (Figure 12). When the value of $T$ is larger, the inventory level of system is relatively higher. At this point, with the climbing demand, the increase in sales revenue is not enough to offset the increase in the inventory. So the annual profit will decrease when $v$ increases.

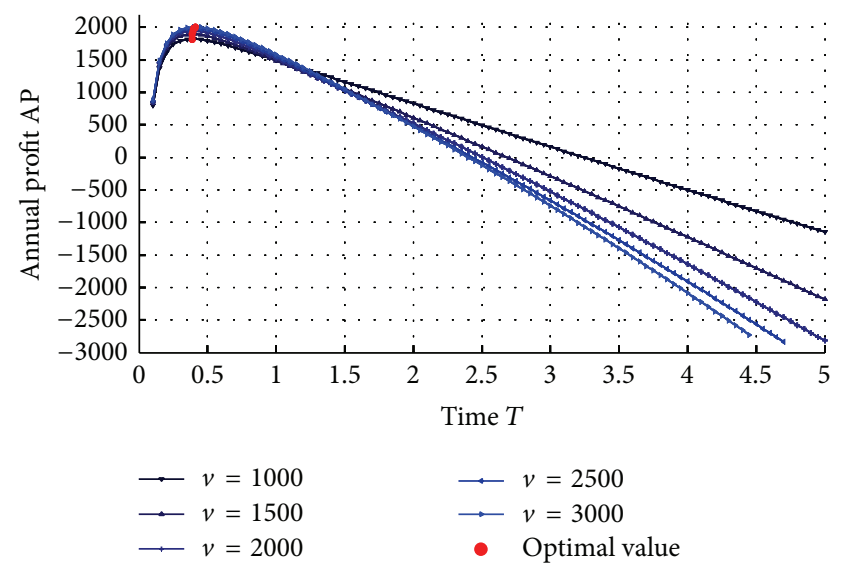

FIGURE 11: The sensitivity analysis of $v$.

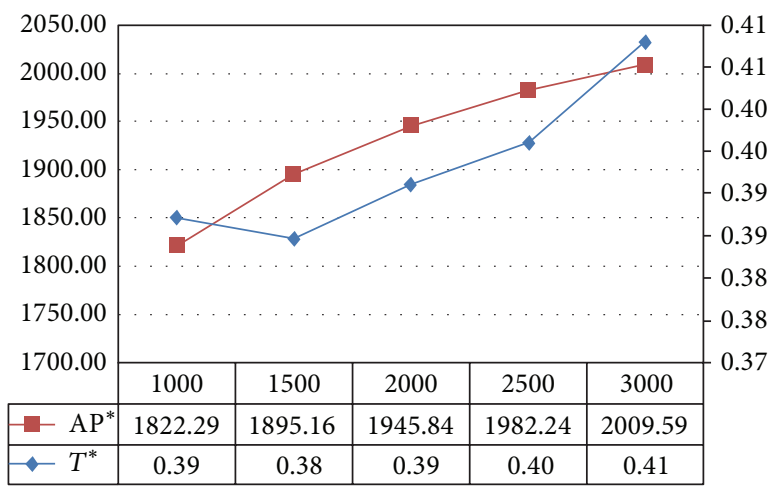

Figure 12: The changing trend of $T^{*}$ and $A P^{*}$ when $v$ changes.

When $v$ increases, the maximum annual profit $A P^{*}$ continues increasing, and the optimal production cycle $T^{*}$ decreases firstly and then increases. For a fixed $T$, when the value of $v$ is small, the system stays at a relatively low inventory level. With an increasing demand, the increase in sales revenue is limited and not enough to offset the increase in the inventory. So when $v$ increases, the optimal production cycle $T^{*}$ needs to be reduced in order to reduce the inventory costs. When the value of $v$ is larger, the inventory level of system is higher and the demand increases considerably, resulting in the fact that the increase in sales revenue is greater than the increase in inventory costs. So when $v$ continues climbing, the optimal production cycle $T^{*}$ will appear as an upward trend.

(6) The Impact of Inventory Holding Cost $h$ on the Optimal Solution. When $h$ increases, the inventory costs will aggrandize with it and the total annual profit will decrease. So decision makers will reduce the production cycle $T$ to reduce the annual average inventory level in order to cut down the inventory costs. When $h$ is larger, the annual profit curve will drop more rapidly with an increasing $T$. 


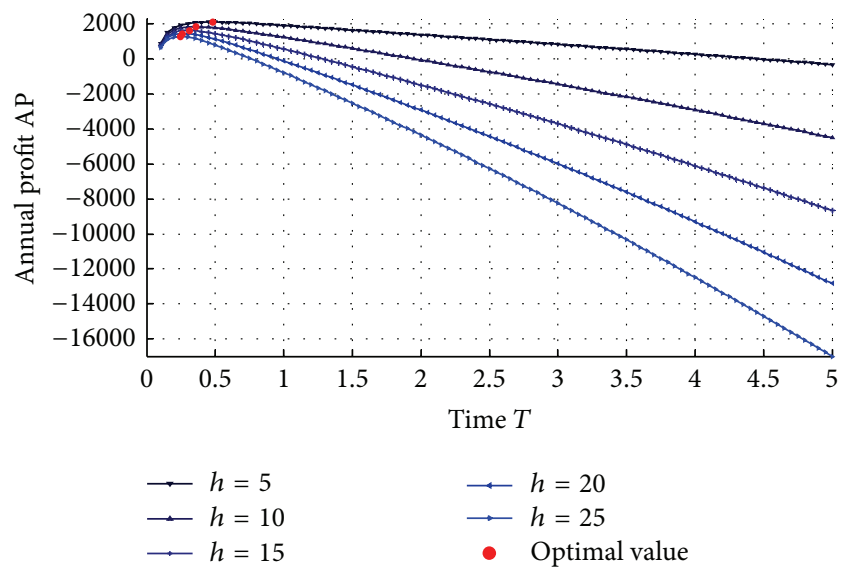

FIgURE 13: The sensitivity analysis of $h$.

\section{Conclusion}

This study has investigated production optimization problem arising from a manufacturing system with likely imperfect production and instantaneously inventory-dependent market demand. We have constructed constrained nonlinear programming models to depict this problem by incorporating the randomness of production imperfectness, inventorydemand dependence, and stock holding space bound. For seeking the optimal annual total profit, an improved artificial fish swarm algorithm combined with tabu search was devised to solve the model with numerical studies and sensitivity analysis. This research adds to our understanding of managing the manufacturing system with new characteristics as discussed in the present paper. It contributes to providing the method and strategy of determining optimum production cycle time to obtain best system performance. This study also shows us the necessity and power of integrate operations and sales. However, the research is limited in several ways. For instance, we only confine our study to a single manufacturer, which can be extended to a supply chain system. Furthermore, we consider the demand is only inventory-dependent with deterministic dependence sensitivity parameter. Other random factors can be added to the demand function in the future research.

\section{Appendix}

Proof 1. Consider

$$
I_{2-2}=\frac{v \gamma e^{b \tau}-(\nu-a)}{b} e^{-b t}+\frac{v(1-\gamma)-a}{b}, \quad \tau \leq t \leq S_{2} .
$$

Seeking the first derivative $d I_{2-2} / d t=\left(v-a-v \gamma e^{b \tau}\right) e^{-b t}$, $e^{-b t}$ is constantly greater than zero. When $\tau \in[0,(1 / b) \ln ((v-$ $a)(v \gamma)], v-a-v \gamma e^{b \tau} \geq 0$, and $d I_{2-2} / d t \geq 0, I_{2-2}(t)$ is an increasing function and the inventory increases in period of $\tau \leq t \leq S_{2}$; when $\tau \in\left((1 / b) \ln ((v-a) / v \gamma), S_{2}\right]$, $v-a-v \gamma e^{b \tau}<0$, and $d I_{2-2} / d t<0, I_{2-2}(t)$ is a decreasing function and the inventory decreases in period of $\tau \leq t \leq S_{2}$.

Proof 2. There is

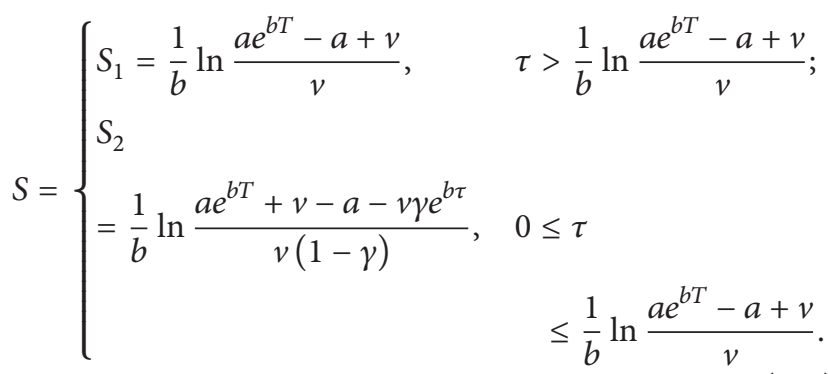

Make $f(\tau)=(1 / b) \ln \left(\left(a e^{b T}+v-a-v \gamma e^{b \tau}\right) / v(1-\gamma)\right)$; it is obvious that when $\tau$ increases, $f(\tau)$ decreases and $f(\tau)$ is the decreasing function of $\tau$. When $\tau=(1 / b) \ln \left(\left(a e^{b T}-\right.\right.$ $a+v) / v)$, then $f(\tau)$ gets the minimum value and $f_{\min }=$ $(1 / b) \ln \left(\left(a e^{b T}+v-a\right) / v\right)=S_{1}$, so $S_{2} \geq S_{1}$.

Proof 3. The inventory constraints are

$$
\begin{aligned}
\text { s.t. } \quad & \frac{a\left[e^{b\left(T-S_{1}\right)}-1\right]}{b} \leq Q_{\max } \\
& \frac{a\left[e^{b\left(T-S_{2}\right)}-1\right]}{b} \leq Q_{\max } \\
& \frac{(a-v)\left(e^{-b \tau}-1\right)}{b} \leq Q_{\max } \\
\Longrightarrow \max & \left(\frac{a\left[e^{b\left(T-S_{1}\right)}-1\right]}{b}, \frac{a\left[e^{b\left(T-S_{1}\right)}-1\right]}{b},\right. \\
& \left.\frac{(a-v)\left(e^{-b \tau}-1\right)}{b}\right) \leq Q_{\max } .
\end{aligned}
$$

From Proof 2, we can know that $S_{2} \geq S_{1}$, and it is obvious that $a\left[e^{b\left(T-S_{1}\right)}-1\right] / b \geq a\left[e^{b\left(T-S_{2}\right)}-1\right] / b$.

There is $a\left[e^{b\left(T-S_{1}\right)}-1\right] / b=a(v-a)\left(e^{b T}-1\right) / b\left(a e^{b T}-a+v\right)$, and make $\varphi(\tau)=(a-v)\left(e^{-b \tau}-1\right) / b$ and $(1 / b) \ln ((v-a) / v \gamma)<$ $\tau \leq(1 / b) \ln \left(\left(a e^{b T}-a+v\right) / v\right)$. Then we can get $v>a$. And when $\tau$ increases, $\varphi(\tau)$ increases and $\varphi(\tau)$ is the increasing function of $\tau$. When $\tau=(1 / b) \ln \left(\left(a e^{b T}-a+v\right) / v\right)$, then $\varphi(\tau)$ reaches the maximum value $\varphi_{\max }=a(v-a)\left(e^{b T}-1\right) / b\left(a e^{b T}-a+\right.$ $v)=a\left[e^{b\left(T-S_{1}\right)}-1\right] / b$. From another layer of significance, there are no defective products in the production process when $=$ $(1 / b) \ln \left(\left(a e^{b T}-a+v\right) / v\right)$. The production process carries the same as case 1 and the maximum inventory is $a\left[e^{b\left(T-S_{1}\right)}-1\right] / b$. 
In summary, we can get

$$
\begin{aligned}
& \max \left(\frac{a\left[e^{b\left(T-S_{1}\right)}-1\right]}{b}, \frac{a\left[e^{b\left(T-S_{1}\right)}-1\right]}{b}, \frac{(a-v)\left(e^{-b \tau}-1\right)}{b}\right) \\
& \leq Q_{\max } \Longrightarrow \frac{a\left[e^{b\left(T-S_{1}\right)}-1\right]}{b} \leq Q_{\max } .
\end{aligned}
$$

The maximum and minimum theorem: assuming that $f(x)$ is continuous on a closed interval $[a, b]$, it must have a minimum and maximum value on $[a, b]$. (An important property for the continuous function on a closed interval)

$$
\begin{aligned}
& a e^{b T}-a+v=v e^{b S}, \\
& S=\frac{1}{b} \ln \frac{a e^{b T}-a+v}{v}, \\
& e^{b S}=\frac{a e^{b T}+v-a-v \gamma e^{b \tau}}{v(1-\gamma)}, \\
& S=\frac{1}{b} \ln \frac{a e^{b T}+v-a-v \gamma e^{b \tau}}{v(1-\gamma)}, \\
& E(S)=\int_{0}^{(1 / b) \ln \left(\left(a e^{b T}-a+v\right) / v\right)} \lambda e^{-\lambda \tau} \\
& \times \frac{1}{b} \ln \frac{a e^{b T}+v-a-v \gamma e^{b \tau}}{v(1-\gamma)} d \tau \\
& +\int_{(1 / b) \ln \left(\left(a e^{b T}-a+v\right) / v\right)}^{+\infty} \lambda e^{-\lambda \tau} \times \frac{1}{b} \ln \frac{a e^{b T}-a+v}{v} d \tau \\
& =\frac{1}{b}\left[\int_{0}^{(1 / b) \ln \left(\left(a e^{b T}-a+v\right) / v\right)} \lambda e^{-\lambda \tau}\right. \\
& \times \ln \frac{a e^{b T}+v-a-v \gamma e^{b \tau}}{v(1-\gamma)} d \tau \\
& \left.+\left(\frac{a e^{b T}-a+v}{v}\right)^{-\lambda / b} \times \ln \frac{a e^{b T}-a+v}{v}\right] .
\end{aligned}
$$

\section{Conflict of Interests}

The authors declare that there is no conflict of interests regarding the publication of this paper.

\section{Acknowledgments}

The authors would like to thank the editors and anonymous referees for their time, patience, and helpful suggestions devoted to the review of this paper. Their constructive comments and suggestions have concretely improved and enriched this paper much further. This work is partially supported by NSFC Grants (no. 71071107).

\section{References}

[1] M. J. Rosenblatt and H. L. Lee, "Economic production cycles with imperfect production processes," IIE Transactions, vol. 18, no. 1, pp. 48-55, 1986.

[2] S. S. Sana, "A production-inventory model in an imperfect production process," European Journal of Operational Research, vol. 200, no. 2, pp. 451-464, 2010.

[3] R. Gupta and P. Vrat, "Inventory model for stock-dependent consumption rate," Opsearch, vol. 23, no. 1, pp. 19-24, 1986.

[4] T. L. Urban, "Inventory models with inventory-level-dependent demand: a comprehensive review and unifying theory," European Journal of Operational Research, vol. 162, no. 3, pp. 792804, 2005.

[5] N. H. Shah and K. T. Shukla, "Optimal production schedule in declining market for an imperfect production system," International Journal of Machine Learning and Cybernetics, vol. 1, no. 1-4, pp. 89-99, 2010.

[6] H. L. Lee and M. J. Rosenblatt, "Simultaneous determination of production cycle and inspection schedules in a production system," Management Science, vol. 33, no. 9, pp. 1125-1136, 1987.

[7] H. L. Lee and M. J. Rosenblatt, "Production and maintenance planning model with restoration cost dependent on detection delay," IIE Transactions, vol. 21, no. 4, pp. 368-375, 1989.

[8] M.-J. Liou, S.-T. Tseng, and T.-M. Lin, "Effects of inspection errors to the imperfect EMQ model," IIE Transactions, vol. 26, no. 2, pp. 42-51, 1994.

[9] C. H. Kim and Y. Hong, "An optimal production run length in deteriorating production processes," International Journal of Production Economics, vol. 58, no. 2, pp. 183-189, 1999.

[10] K.-J. Chung and K.-L. Hou, "An optimal production run time with imperfect production processes and allowable shortages," Computers and Operations Research, vol. 30, no. 4, pp. 483-490, 2003.

[11] C.-Y. Guo, J.-S. Hu, and L. Wang, "Economic production quantity models for items with defective rate and shortages in fuzzy environment," Computer Integrated Manufacturing Systems, vol. 14, no. 11, pp. 2161-2166, 2008.

[12] J.-S. Hu, Y.-P. Ji, C.-Y. Guo, and R.-Q. Xu, "Fuzzy random imperfect production system with shortages," Control and Decision, vol. 26, no. 2, pp. 213-220, 2011.

[13] R. I. Levin, C. P. McLaughlin, R. P. Lamone, and J. F. Kottas, Productions Operations Management: Contemporary Policy for Managing Operating Systems, McGraw-Hill, New York, NY, USA, 1972.

[14] E. A. Silver and R. Peterson, Decision Systems for Inventory Management and Production Planning, John Wiley \& Sons, New York, NY, USA, 2nd edition, 1982.

[15] B. N. Mandal and S. Phaujdar, "An inventory model for deteriorating items and stock-dependent consumption rate," Journal of the Operational Research Society, vol. 40, pp. 483-488, 1989.

[16] T. K. Datta and A. K. Pal, "Note on an inventory model with inventory-level-dependent demand rate," Journal of the Operational Research Society, vol. 41, no. 10, pp. 971-975, 1990.

[17] V. M. Dixit and N. H. Shah, "A production inventory model for exponentially increasing demand and production," Modeling, Measurement and Control, vol. 22, no. 3-4, pp. 15-24, 2001.

[18] R. C. Baker and T. L. Urban, "Deterministic inventory system with an inventory level-dependent demand rate," Journal of Operational Research Society, vol. 39, no. 9, pp. 823-831, 1988. 
[19] H. Soni and N. H. Shah, "Optimal ordering policy for stockdependent demand under progressive payment scheme," European Journal of Operational Research, vol. 184, no. 1, pp. 91-100, 2008.

[20] J. Min, Y.-W. Zhou, and J. Zhao, "An inventory model for deteriorating items under stock-dependent demand and twolevel trade credit," Applied Mathematical Modelling, vol. 34, no. 11, pp. 3273-3285, 2010.

[21] N. H. Shah, A. R. Patel, and K.-R. Lou, "Optimal ordering and pricing policy for price sensitive stock-dependent demand under progressive payment scheme," International Journal of Industrial Engineering Computations, vol. 2, no. 3, pp. 523-532, 2011.

[22] J.-T. Teng, I.-P. Krommyda, K. Skouri, and K.-R. Lou, "A comprehensive extension of optimal ordering policy for stockdependent demand under progressive payment scheme," European Journal of Operational Research, vol. 215, no. 1, pp. 97-104, 2011.

[23] Y.-W. Zhou, Y. Zhong, and J. Li, "An uncooperative order model for items with trade credit, inventory-dependent demand and limited displayed-shelf space," European Journal of Operational Research, vol. 223, no. 1, pp. 76-85, 2012.

[24] M. Goh, "EOQ models with general demand and holding cost functions," European Journal of Operational Research, vol. 73, no. 1, pp. 50-54, 1994.

[25] H.-M. Wee, "Joint pricing and replenishment policy for deteriorating inventory with declining market," International Journal of Production Economics, vol. 40, no. 2-3, pp. 163-171, 1995.

[26] G. Padmanabhan and P. Vrat, "EOQ models for perishable items under stock dependent selling rate," European Journal of Operational Research, vol. 86, no. 2, pp. 281-292, 1995.

[27] J. Ray and K. S. Chaudhuri, "An EOQ model with stockdependent demand, shortage, inflation and time discounting," International Journal of Production Economics, vol. 53, no. 2, pp. 171-180, 1997.

[28] B. R. Sarker, S. Mukherjee, and C. V. Balan, "An order-level lot size inventory model with inventory-level dependent demand and deterioration," International Journal of Production Economics, vol. 48, no. 3, pp. 227-236, 1997.

[29] B. C. Giri and K. S. Chaudhuri, "Deterministic models of perishable inventory with stock-dependent demand rate and nonlinear holding cost," European Journal of Operational Research, vol. 105, no. 3, pp. 467-474, 1998.

[30] H. Yan and T. C. E. Cheng, "Optimal production stopping and restarting times for an EOQ model with deteriorating items," Journal of the Operational Research Society, vol. 49, no. 12, pp. 1288-1295, 1998.

[31] M. Mandal and M. Maiti, "Inventory of damagable items with variable replenishment rate, stock-dependent demand and some units in hand," Applied Mathematical Modelling, vol. 23, no. 10, pp. 799-807, 1999.

[32] K.-J. Chung and S.-F. Tsai, "Inventory systems for deteriorating items with shortages and a linear trend in demand-taking account of time value," Computers \& Operations Research, vol. 28, no. 9, pp. 915-934, 2001.

[33] X. L. Li, A new intelligent optimization-artificial fish swarm algorithm [Ph.D. thesis], Zhejiang University, Zhejiang, China, 2003.

[34] H. Peng, Research on the production strategy and payment policy for the items with inventory-dependent demand [M.S. thesis], College of Management and Economics, Tianjin University, Tianjin, China, 2013.
[35] M. Neshat, G. Sepidnam, M. Sargolzaei, and A. N. Toosi, "Artificial fish swarm algorithm: a survey of the state-of-the-art, hybridization, combinatorial and indicative applications," Artificial Intelligence Review, vol. 42, no. 4, pp. 965-997, 2012.

[36] X. Li, Z. Shao, and J. Qian, "An optimizing method based on autonomous animats: fish-swarm algorithm," Systems Engineering-Theory \& Practice, vol. 22, no. 11, pp. 32-38, 2002.

[37] L. Li, S.-C. Chi, and G. Lin, "Tabu fish swarm algorithm and its application to slope stability analysis," Engineering Mechanics, vol. 23, no. 3, pp. 6-10, 2006.

[38] C.-R. Wang, C.-L. Zhou, and J.-W. Ma, "An improved artificial fish-swarm algorithm and its application in feed-forward neural networks," in Proceedings of the International Conference on Machine Learning and Cybernetics (ICMLC '05), pp. 2890-2894, Guangzhou, China, August 2005.

[39] H. Huang and Y. Zhou, "A global optimization complex functions method based on improved artificial fish swarm algorithm," Journal-Guangxi Normal University (Natural Science Edition), vol. 26, no. 1, pp. 194-197, 2008.

[40] G. Z. Chen, J. Q. Wang, C. J. Li, and X. Lu, "An improved artificial fish swarm algorithm and its applications," Systems Engineering, vol. 27, no. 12, pp. 105-110, 2009.

[41] Y. Cheng, M. Jiang, and D. Yuan, "Novel clustering algorithms based on improved artificial fish swarm algorithm," in Proceedings of the 6th International Conference on Fuzzy Systems and Knowledge Discovery (FSKD '09), vol. 3, pp. 141-145, IEEE, Tianjin, China, August 2009.

[42] Y. Peng, "An improved artificial fish swarm algorithm for optimal operation of cascade reservoirs," Journal of Computers, vol. 6, no. 4, pp. 740-746, 2011.

[43] H.-C. Tsai and Y.-H. Lin, "Modification of the fish swarm algorithm with particle swarm optimization formulation and communication behavior," Applied Soft Computing Journal, vol. 11, no. 8, pp. 5367-5374, 2011.

[44] X. Zheng, The improvement and application for the artificial fish swarm algorithm [M.S. thesis], Shanghai Maritime University, Pudong, China, 2006. 


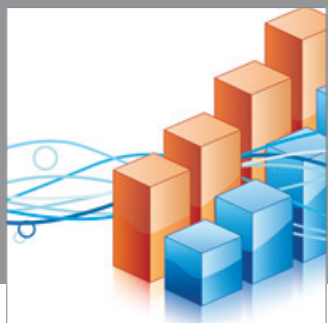

Advances in

Operations Research

mansans

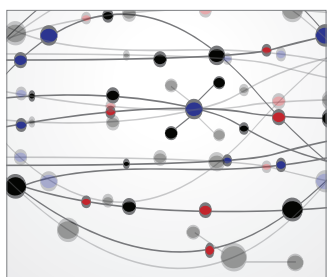

The Scientific World Journal
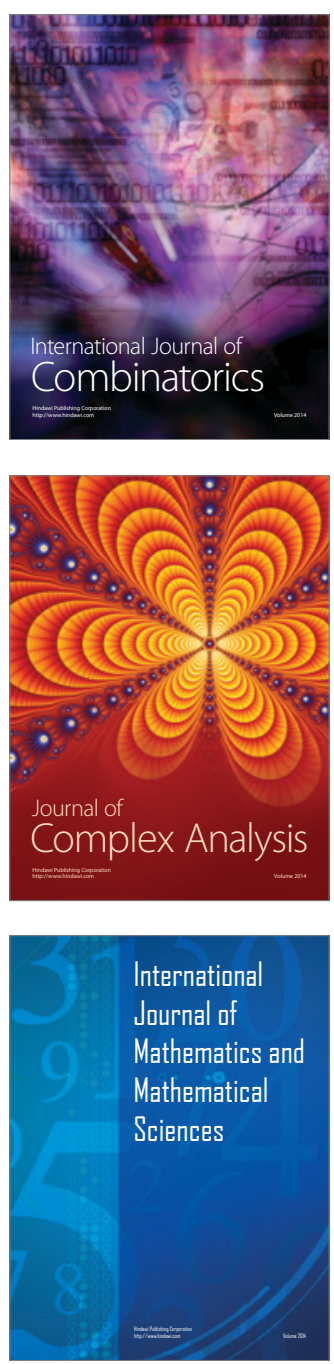
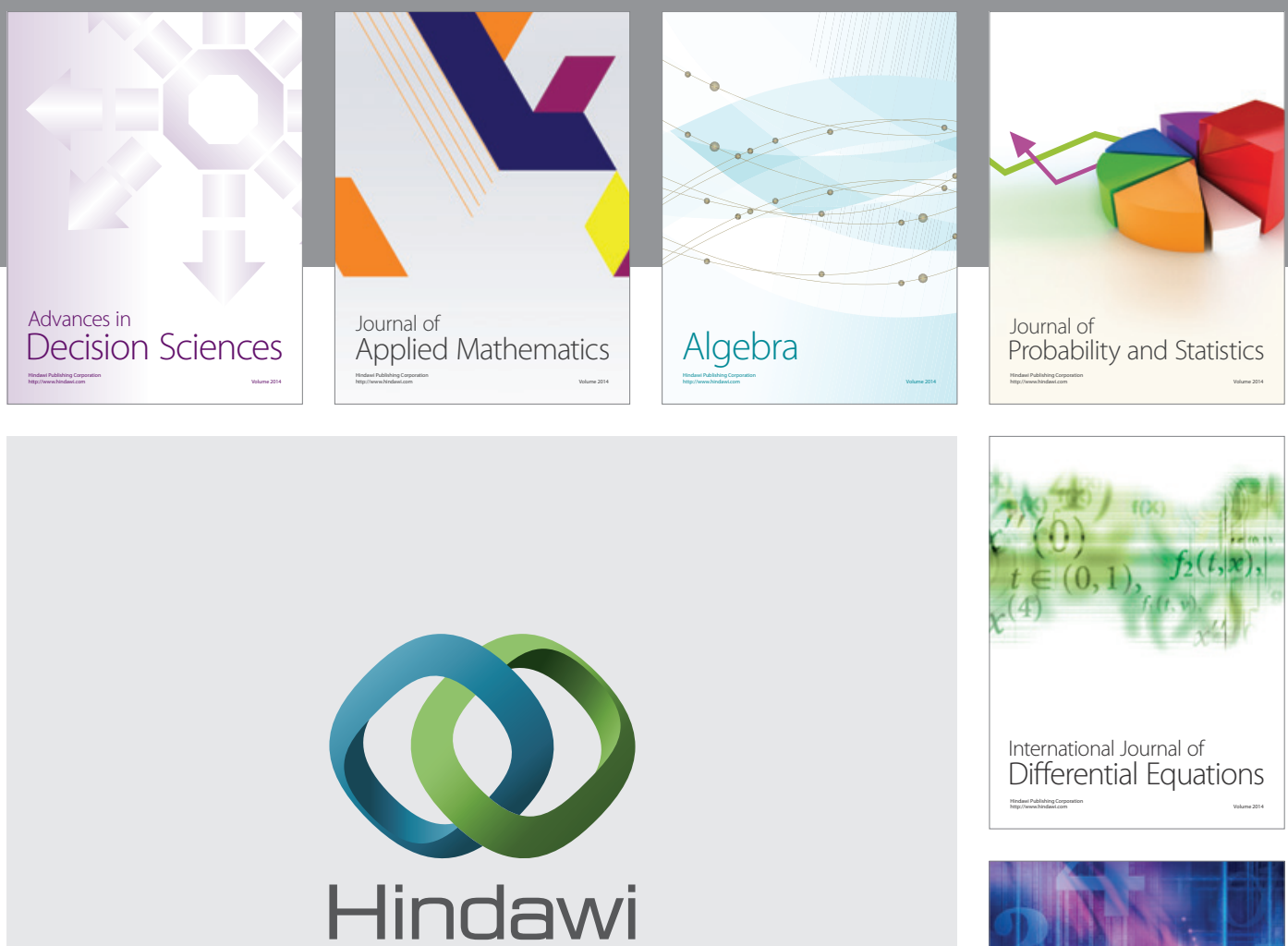

Submit your manuscripts at http://www.hindawi.com
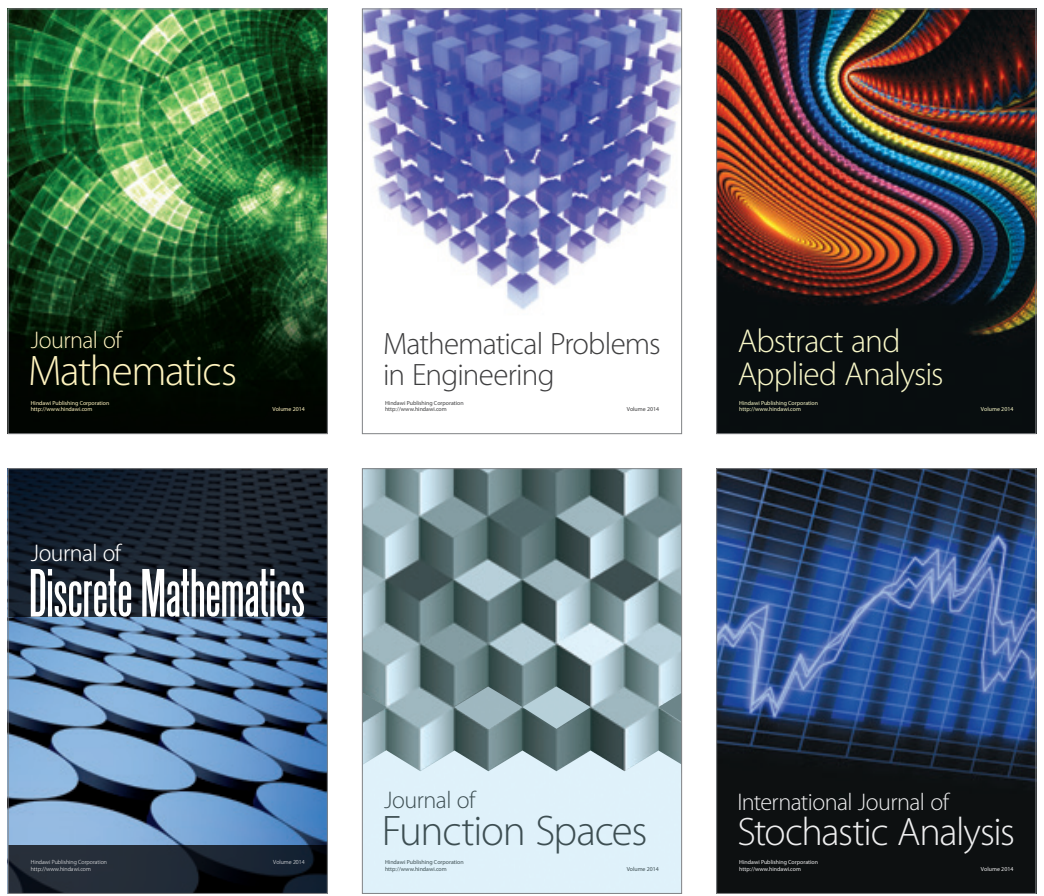

Journal of

Function Spaces

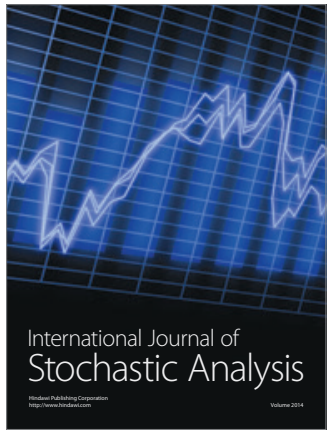

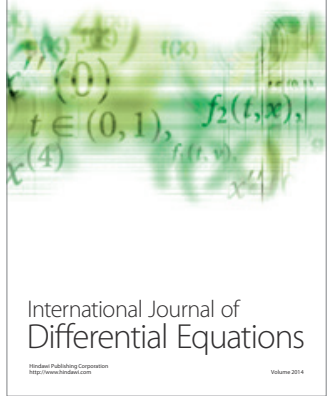
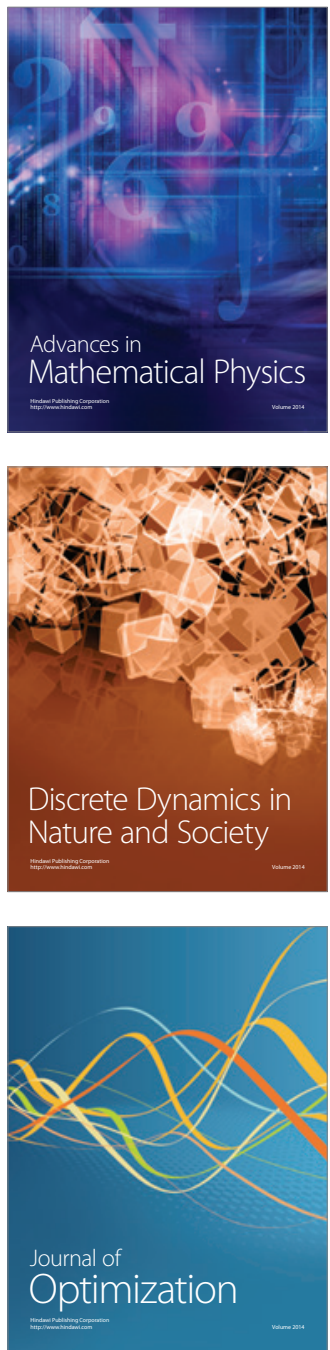